\title{
FILIACIONES, HUELLAS LITERARIAS, REESCRITURAS: CINCO NOVELAS ECUATORIANAS
}

\author{
Alicia Ortega Caciedo \\ Universidad Andina Simón Bolívar, Sede Ecuador \\ alicia.ortega@uasb.edu.ec
}

Resumen: El artículo estudia un conjunto de novelas ecuatorianas - publicadas en el curso del nuevo siglo-, que explícitamente evidencian, y problematizan, el diálogo con su propia tradición narrativa. Sus autores recurren a estrategias de apropiaciones, reescrituras, hurtos y "correcciones", en un juego de amplias resonancias intertextuales y metaliterarias. El corpus de estudio lo conforman cinco novelas: El pinar de Segismundo (2008), de Eliécer Cárdenas; Oscurana (2011), de Luis Carlos Mussó; Memorias de Andrés Chiliquinga (2013), de Carlos Arcos; Tatuaje de náufragos (2008), de Jorge Velasco Mackenzie, La desfiguración Silva (2014), de Mónica Ojeda. Las novelas mencionadas se construyen alrededor de una red de relaciones y referencias a otros textos, en donde la literatura misma deviene archivo y fuente de nuevas escrituras. Interesa pensar la construcción de una línea de filiaciones y genealogías literarias, la memoria afectiva como detonante de un deseo de escritura, la presencia del nombre propio como disparador de sentidos, la producción de pensamiento y debates desde la imaginación literaria, la aparición de escritores y personajes en calidad de fantasmas que interpelan al escritor contemporáneo en calidad de heredero de una tradición. Los autores de las novelas discutidas son, ante todo, lectores de una tradición narrativa: escriben desde una biblioteca compartida, y desde una particular relación afectiva con personajes, libros y escritores que habitan la memoria literaria. Interesa leer la novelística contemporánea como escenificación de un legado, así como un ejercicio de rememoración, reescrituras y trabajo en comunidad.

Palabras clave: literatura ecuatoriana contemporánea, novela ecuatoriana, vigencia de Jorge Icaza y Pablo Palacio, Eliécer Cárdenas, Luis Carlos Mussó, Caros Arcos, Jorge Velasco Mackenzie, Mónica Ojeda

\begin{abstract}
The last years The article studies a set of Ecuadorian novels - published in the course of the new century - that explicitly make evident and problematize the dialogue with their own narrative tradition. Their authors resort to strategies of appropriation, rewriting, theft and "corrections", in a game with extensive intertextual and meta-literary resonances. The corpus of study is made up of five novels: El pinar de Segismundo (2008), by Eliécer Cárdenas; Oscurana (2011), by Luis Carlos Mussó; Memorias de Andrés Chiliquinga (2013), by Carlos Arcos; Tatuaje de náufragos (2008), by Jorge Velasco Mackenzie, La desfiguración Silva (2014), by Mónica Ojeda. The aforementioned novels are built around a network of relationships and references to other texts, where literature itself becomes a source and archive of new writings. It is interesting to think of the construction of a line of affiliations and literary genealogies, affective memory as a detonator of a desire for writing, the presence of the proper name as a trigger of senses, the production of thought and debates from the literary imagination, the appearance of writers and characters as ghosts that challenge the contemporary writer as heirs to a tradition. The authors of the novels discussed are, above all, readers of a narrative tradition: they write from a shared library, and from a particular affective relationship with characters, books and writers who inhabit literary memory. It is interesting to read contemporary novels as the staging of a legacy, as well as an exercise in remembrance, rewriting and working in community.
\end{abstract}

Keywords: Contemporary Ecuadorian literature, Ecuadorian novel, validity of Jorge Icaza and Pablo Palacio, Eliécer Cárdenas, Luis Carlos Mussó, Caros Arcos, Jorge Velasco Mackenzie, Mónica Ojeda 
Leo aquí cinco novelas desde una mirada que busca destacar la escritura literaria, ante todo, como un acto de lectura: El pinar de Segismundo (2008), de Eliécer Cárdenas; Oscurana (2011), de Luis Carlos Mussó; Memorias de Andrés Chiliquinga (2013), de Carlos Arcos; Tatuaje de náufragos (2008) de Jorge Velasco Mackenzie, La desfiguración Silva (2014) de Mónica Ojeda. ${ }^{1}$ Estas novelas articulan una suerte de hiperconciencia narrativa, en el esfuerzo por escenificar el diálogo con su propia tradición. El centenario del nacimiento de Jorge Icaza y Pablo Palacio, en el 2006, generó una serie de relecturas y celebraciones críticas para pensar el lugar de estos escritores en el marco de nuestra memoria literaria. Las novelas mencionadas se construyen al interior de una red de relaciones y referencias a otros textos, en donde la literatura misma deviene archivo y fuente de nuevas escrituras. Este archivo se ve sometido a múltiples mecanismos de apropiaciones y reminiscencias, en un juego de alusiones y citas que produce una escritura de amplias resonancias intertextuales. El corpus seleccionado evidencia no solamente una suerte de re-escritura de la tradición, sino que propone, a la vez, un trabajo con la memoria: traslada a la escena contemporánea huellas de un pasado literario, desde una explícita filiación afectiva. En las novelas seleccionadas, resulta central, como elemento disparador de sentidos, la aparición del nombre propio de otros escritores ecuatorianos. Derrida llama la atención, en su lectura sobre Paul de Man, acerca del poder del "nombre

\footnotetext{
${ }^{1}$ Buena parte de este trabajo ha sido realizado con el apoyo del Comité de Investigación de la Universidad Andina Simón Bolívar, Sede Ecuador, de la que soy docente a tiempo completo en el Área de Letras.
} 
desnudo" al momento de su invocación: activación de memoria, posibilidad de magia puesto que acerca a quien está ausente, deseo de dejar hablar a otro, afirmación de filiación y reconocimiento.

\section{1.- En la biblioteca}

En "Palabras finales" de El pinar de Segismundo (2008), Eliécer Cárdenas indica que la novela "fue escrita por el autor cuando se conmemoraba en Ecuador el centenario del nacimiento de Jorge Icaza e iba a cumplirse el cincuentenario de la tardía aparición de la novela Égloga trágica de Gonzalo Zaldumbide. A partir de aquellas polaridades dentro de la literatura ecuatoriana de aquella época, el autor quiso ofrecer en esta novela una historia un poco policial, otro tanto irónica y festiva, pero entrañable, acerca de una época, con personajes que salvo unos pocos llevan los nombres de sus referentes reales, pero construidos de y por la ficción" (p. 167). Efectivamente, Icaza y Zaldumbide entran en la novela junto con otros escritores y artistas que protagonizaron el medio literario durante la primera mitad del siglo pasado: César Dávila, G. H. Mata, Oswaldo Guayasamín, entre otros; "amigos y cofrades" vinculados a la Casa de la Cultura bajo el liderazgo del crítico Benjamín Carrión. La operación de nominación de los personajes, en función de un referente literario real, teje una escritura que seduce al lector por efecto de una especial familiaridad que la sola mención de los nombres hace posible. De entrada, el nombre propio establece 
los términos de un pacto de lectura, puesto que los personajes portan una sobrecarga de sentidos en función del lugar que ocupan al interior de una memoria literaria compartida. El solo reconocimiento provoca en el lector un particular placer, porque todo un acumulado de conocimiento se activa ante la enunciación del nombre propio. "Conocer es reconocer", advierte Paul Ricoeur, en el contexto de una reflexión acerca de la memoria y, en particular, de lo que el filósofo francés denomina "pequeña felicidad de la percepción": cuando reaparecen los ausentes, en nuestro caso, por efecto de una escritura que parece ampliar el círculo de los próximos y los allegados.

Los personajes, sujetos históricos reales, son retratados en la novela de Cárdenas en su dimensión más cotidiana: pasiones personales, pequeñas venganzas y rivalidades, complicidades y búsquedas, en el desarrollo de una lograda trama que porta las huellas de otros textos -escondidos y asimilados- a manera de una sobre-determinación intertextual (Boletin y elegía de las mitas, de Jorge Carrera Andrade, El Chulla Romero y Flores, de Jorge Icaza, como ejemplos). La trama -una conspiración de artistas e intelectuales- está cargada de humor e imaginación, en la construcción de una escritura que fluye y reinventa creativamente los datos que ofrece la historia. En el presente narrativo, 1956, Icaza, Mata, Dávila, Guayasamín, son convocados en la biblioteca de la casa del crítico Benjamín Carrión, por su secretario privado. Los confabulados deben cumplir una secreta misión, que consiste en robar los 
manuscritos dispersos y ocultos de Égloga trágica, ${ }^{2}$ con el fin de minar la salud emocional de Zaldumbide e impedir su candidatura como binomio de Camilo Ponce en las próximas elecciones. La línea argumentativa se complejiza, puesto que el presente narrativo enmarca la visita al país de una embajada artística en representación del gobierno franquista. Paralelamente, se narra la llegada a Quito del poeta español en exilio León Felipe y, por otro lado, la presencia clandestina de Carlos Guevara Moreno -fundador y líder de la denominada Concentración de Fuerzas Populares (CFP)- recupera episodios del impacto que tuvo la Guerra Civil Española entre los intelectuales ecuatorianos. La biblioteca personal de Carrión, la librería de Icaza, el Teatro Sucre, la Casa de la Cultura, la calle de la Ronda, la biblioteca jesuita de Cotocollao, un obraje colonial de la hacienda El Pinar (el lugar en donde transcurren los sucesos narrados en la novela de Zaldumbide, Égloga trágica), son escenarios, entre otros, de encuentros y diálogos en los que, desde la perspectiva que posibilita la enunciación en tiempo presente, reconocemos trazos de proyectos estéticos y políticos que definieron los términos de un debate intelectual aún vigente: populismo, mestizaje, cultura nacional, proyecto indigenista, internacionalismo y militancia

\footnotetext{
2 Vale destacar que Agustín Cueva identificó la publicación de Égloga trágica como uno de los "tres momentos de la conciencia feudal ecuatoriana". En ella, los personajes indios aparecen como mero decorado estilizado, quienes, junto con las mujeres, son representados como seres inferiores: "El amor y la política, tal como son concebidos en Égloga trágica, reflejan también una concepción típicamente feudal" (Cueva, p. 99). Más adelante, Cueva señala: "Zaldumbide es un 'estilista', en la medida en la que así se decida denominar a quien toma partido por el diccionario y la preceptiva, en contra del lenguaje vivo" (p. 106). Estos señalamientos marcan una importante pauta en la novela de Cárdenas, para comprender los alcances de la crítica bajo el enmascaramiento de la broma y el enredo policial.
} 
política de izquierda, conciencia feudal y valoración crítica de matriz hispanista.

Las siguientes palabras, que Cárdenas hace pasar por autoría de Icaza, bien pueden ser leídas como una suerte de arte poética del autor: "Que el mundo era un rompecabezas donde ciertos pedazos se unían como al antojo de algún escritor incógnito, omnisciente..." (p. 82). Ciertamente, la novela ofrece al lector un conjunto de anécdotas que, aunque producto de la ficción, producen un efecto de totalidad que hilvana y articula disímiles elementos de la historia "real" (los pedazos del rompecabezas). Elementos que, bajo una nueva composición -la novela que leemos- resignifican la historia, la actualizan y jalonan hacia el presente. Bajo esta nueva disposición de los elementos, asistimos, por ejemplo, a un insólito lance de amor entre el novelista Icaza y la Lola Flores, que ha llegado como parte de la caravana española. Cárdenas reescribe, con estos nuevos protagonistas, el episodio en que Icaza (en su novela El Chulla Romero y Flores) narra el primer encuentro entre el Chulla con Rosario, luego del baile de las embajadas. Así también, el desenlace "policial" con respecto al hurto de los manuscritos -cuyo autor intelectual resulta ser el hijo de la Mariucha, la joven india de la novela de Zaldumbide, violada por el joven terrateniente- actualiza el debate en torno a la llamada novela indigenista y el lugar del mestizo en la sociedad ecuatoriana. Esta rica interacción dialógica, en la que varias narraciones se encuentran, nos devuelve, en tanto lectores, a una biblioteca original que no deja de reinventarse: aquella que pervive en nuestra memoria y hace posible el juego intertextual que revitaliza y desempolva los textos canonizados. 
Los escritores del pasado nos interpelan desde la lúdica, y lúcida, carnalidad de una escritura que los reinventa y actualiza.

\section{2.- En el archivo}

Pablo Palacio constituye el motivo central de Oscurana, la novela de Luis Carlos Mussó (2011). Más concretamente, sus últimos años en la sección psiquiátrica del Hospital Luis Vernaza de Guayaquil, como paciente de la cama 27. El presente narrativo ancla en 1996, al momento en que dos jóvenes procuran recabar la mayor cantidad de datos posibles sobre la vida y obra del escritor lojano, para concluir una tesis postergada. Algunos capítulos rememoran episodios ligados a la trayectoria vital de Palacio, simulan la voz del escritor y traen a la escena narrativa diálogos en los que no es difícil reconocer el nombre propio de sus contemporáneos, así como el escenario urbano (Quito y Guayaquil) y los avatares políticos de los años treinta y cuarenta. La novela se construye sobre la base de información recolectada en un archivo múltiple y disperso: acontecimientos biográficos (con particular énfasis, el cuidado de su esposa Carmen Palacios durante la enfermedad y la reclusión sanatoria, así como jornadas de tertulias y aventuras compartidas con sus compañeros de generación), detalladas descripciones fisonómicas, testimonios y recuerdos de quienes lo conocieron, rupturas y polémicas literarias, valoraciones críticas, fragmentos de sus escritos -a partir de un trabajo de intertextualidad marcada, que permite al lector rastrear y reconocer las huellas de textos escondidos. En suma, 
libros, tesis, antologías, catálogos, planos de las ciudades recorridas por Palacio, entrevistas, homenajes, recortes de periódicos y revistas, conforman el archivo Pablo Palacio que articula la novela y que, a la vez, se erige como horizonte de lectura. Un archivo trasegado por el novelista, manipulado y reinventado en la construcción de una suerte de archivo apócrifo: el nuevo archivo, re-escrito, sustenta el desarrollo de una ficción que incluye una pieza de teatro en un solo acto (en donde uno de los personajes es el fantasma de Pablo Palacio), así como el guión de un corto documental en el que aparece Palacio nonagenario y la referencia a la escritura falsificada, por los dos tesistas, de una novela inédita del escritor vanguardista de la que solamente sobrevivió el título y la anécdota de sus manuscritos perdidos.

Tras las huellas de Palacio, la voz narrativa se multiplica: en segunda persona, bajo el nombre de Alejandro, un locutor de radio, junto con Roberto, emprende una investigación, en principio académica, que conduce, en la escritura de la novela que leemos, a una radical modificación del archivo palaciano: los jóvenes investigadores escriben, imitando el estilo de Palacio, su novela perdida, Ojeras de virgen (de cuya existencia sabemos solamente por referencias biográficas y testimoniales de sus contemporáneos). Al interior de la trama anecdótica, se trata de una novela falsificada que los protagonistas ponen a circular entre los cachineros (vendedores de cosas usadas o robadas) de Guayaquil, desde donde es "recuperada" por la academia, aunque las noticias mencionan un archivo de actas antiguas en la Biblioteca Municipal del puerto. Tal es así que los medios anuncian la publicación de las Obras completas 
definitivas, editadas por la UNESCO. Escrituras apócrifas, hurtos, imitaciones, versiones inventadas, problematizan la noción de autoría y burlan el circuito académico de seguridad que aspira frenar el trasiego de material ilícito. Una broma prolijamente pensada al mejor estilo palaciano. Contrasta las imágenes del deterioro físico y mental del escritor -la sombra que sobrevive como resto de sí mismo- con la fuerza y radical originalidad de sus escritos que propositivamente contaminan la novela (gesto de tributo y, a la vez, ofrenda de morada para quien pervive con descomunal fuerza seductora en el presente), así como con el recuerdo que preservan de él quienes lo conocieron. Más aún, lo que parece interesar al autor de Oscurana es convocar la materialidad de Pablo Palacio: su voz, su vitalidad corporal, la fuerza de su escritura, la sombra no como resto de un cuerpo enfermo sino como fantasma cuya intempestiva aparición disloca el orden de las temporalidades. Aparece en la novela, en lenguaje derridiano, esa "cosa" difícil de nombrar, que no es ni alma ni cuerpo: el retorno de ese "ser-ahí de un ausente" expresa la fuerza, y la potencia afectiva, de una memoria literaria asediada por la escritura palaciana -su vigencia, la efectividad interpelativa de una voz que viene del pasado y desde allí se actualiza en el presente.

Entre los testimonios recogidos, algunas versiones se refieren a un Pablo Palacio todavía vivo:

Mire, señor, hace años que conozco a Pablito. Es rebuena gente. Dormía en las aceras, ¿'sabe?, envuelto en papel de periódicos; pero ahora duerme en un espacito del sótano [...]. Tiene como 90 años [...]. Siempre pide papel para 
escribir, así que le paso un cuaderno tras otro [...]. La letra le ha cambiado bastante, le falla la vista. Pero escribe las mismas historias. Me acuerdo de tres: Brujerías, El antropófago y la otra Luz lateral (Mussó, p. 283).

Es el testimonio del conserje de un edificio, en el centro de la ciudad. Palacio no solo está vivo, sino que es entrevistado e incluso filmado. Frente al recuerdo de quienes lo conocieron y testimonian los primeros síntomas de su enfermedad, así como el radical deterioro durante los años de hospitalización psiquiátrica, la visibilidad fabulada de Pablo Palacio se sostiene en una lectura que lo conjura, en el esfuerzo por hacer realidad el deseo imposible de convertir a un ser de ficción en uno de carne y hueso.

Hacia el final, la imagen congelada de Palacio, envejecido, es capturada en una pantalla. Mientras tanto, Alejandro y Roberto afirman no tener nada para la tesis, "pero tenemos algo sobre su vida". La novela intercala fragmentos de una suerte de escritos autobiográficos de Palacio (también apócrifos), a modo de diario. En ellos, leemos lo siguiente: "Alguien que me invita al futuro llenándome de preguntas sobre literatura, politica, filosofía. Alguien del que no bay que sentir el menor temor y de cuya presencia estoy completamente seguro" (p. 169, cursivas en el original). No resulta difícil advertir, en las líneas citadas, un juego de espejos que multiplica un deseo de lectura: Mussó, escritor, se proyecta a sí mismo en el lector imaginariamente previsto por Pablo Palacio. Así, es el deseo de lectura el que provoca en el archivo un movimiento expansivo. Su reinvención pasa por la demanda de un lector adicto $y$ apasionado, puesto que provoca una "lectura deseante", en 
palabras de Barthes (1994). Toda lectura, nos propone el semiótico francés, respeta la estructura del texto leído, pero al mismo tiempo la pervierte y desordena. Derrida ha destacado lo que denomina "violencia archivadora", en tanto, en principio, todo archivo es a la vez "instituyente y conservador" (1997, p. 15). En el caso de Oscurana, el archivo original, en el proceso de su narrativización, es consultado e intervenido para devenir escritura apócrifa: la invención de un Palacio que sobrevive como fantasma en la multiplicación de una suma de textos nunca clausurados. El archivo es asumido como lugar de un saber, de una memoria afectiva, y de un deseo que pone en movimiento nuevas escrituras. Este archivo parece reproducirse sin cesar bajo la lógica de los primeros síntomas de su propio autor, en el proceso de su enfermedad: "empezó con eso de que escupía palabras y que había que cambiar las escupideras a cada momento porque se llenaban" (Mussó, p. 244).

\section{3.- En la escritura}

Andrés Chiliquinga, protagonista de la novela de Carlos Arcos (2014), es un indígena Otavalo que, en el verano del 2000, asiste a la Universidad de Columbia, como estudiante invitado en un curso doctoral de Literaturas Andinas. En calidad de dirigente de la Conaie -y como resultado de su participación en el derrocamiento del entonces presidente 
Jamil Mahuad $-^{3}$ ha recibido una invitación de la Comisión Fulbright para conocer la cultura norteamericana. En el marco del curso, Chiliquinga debe preparar una exposición de Huasipungo, con el cometido de observar si el libro refleja la realidad del mundo indígena. Chiliquinga es músico y comerciante de artesanías en ferias europeas, e inicialmente muestra resistencia para emprender la lectura de un libro al que percibe ajeno. Para el cumplimiento de esta tarea recibe la ayuda de una compañera de la misma clase, María Clara Pereira, también ecuatoriana. Las conversaciones que ambos mantienen en la biblioteca universitaria, y el análisis que los estudiantes presentan en clase acerca del corpus novelístico asignado, definen en la novela una explícita dimensión metaliteraria alrededor de la temática indigenista. En el inicio de esos diálogos, Arcos coloca en boca de María Clara lo que se revela como eje de su proyecto escriturario:

Si haces un buen trabajo podría ser el primer artículo sobre Icaza y sobre Huasipungo escrito por un kichwahablante.

\footnotetext{
${ }^{3}$ Con bancos cerrados, depósitos congelados, una inflación galopante, incremento del desempleo y el anuncio de la dolarización en la coyuntura de una crisis económica generalizada, la Conaie (Confederación de Nacionalidades indígenas del Ecuador) convocó a un levantamiento indígena. Indígenas de la Conaie, militares de rango medio, organizaciones sociales y sectores de izquierda de Quito participaron en la ocupación del Congreso, la Corte Suprema de Justicia y por pocas horas el Palacio Presidencial de Carondelet, el 21 de enero de 2000. Estos sucesos (los acontecimientos desarrollados entre el 17 y el 21 de enero) son relatados en la novela por Andrés Chiliquinga, desde la perspectiva de su participación y movilización. Interesante la narración, porque el relato pone el acento en la intervención de jóvenes indígenas metaleros y punkeros que desajustan el estereotipo de lo indio: “-_'FFuera todos!', gritábamos y les amenazábamos con los puños. Nos tomamos el Congreso. Los militares le quitaron el apoyo al Mahuad, se formó un gobierno en el que nosotros participábamos y que duró poquísimo, hasta que los mismos militares que nos habían apoyado, la verdad utilizado, negociaron para que el Vicepresidente, el Gustavo Noboa, reemplazara el Mahuad. Ahí terminó todo. En mayo me invitaron al curso y aquí me tienen" (Arcos, p. 64).
} 
(...) El punto es saber cómo miras la manera en que un autor mestizo los describió a ustedes. Especialmente tú, que eres dirigente de la Conaie, del movimiento indígena más importante de América Latina y que, por lo que sé, ha cambiado la historia del Ecuador (Arcos, p. 37).

En un trabajo de aliento comparativo entre la literatura de Perú y Ecuador, Alejandro Moreano señala que en Ecuador, después de Icaza, no se encuentran momentos similares a los de Arguedas y Scorza. ${ }^{4}$ Esta observación está enmarcada en una reflexión que busca reconocer, en un corpus contemporáneo andino, líneas de continuidad y ruptura con respecto a la literatura indigenista y neoindigenista. La paradoja, a la mirada de Moreano, resulta insólita al considerar que en el periodo de los ochenta se produjo la emergencia de los pueblos indios que, a partir del levantamiento en la década de 1990, se convirtieron en protagonistas centrales de la vida política ecuatoriana y núcleo de irradiación de los movimientos indígenas de América. Con el propósito de ensayar respuestas de interpretación, Moreano busca comprender el efecto que ha tenido en el campo literario ecuatoriano la drástica y radical ruptura con el realismo y la Generación del 30. Una ruptura que no ha dejado de renovarse a lo largo de la segunda mitad del siglo veinte, bajo la forma de un "interminable matricidio", en palabras del crítico (huida del huasipungo, de Mama Pacha,

\footnotetext{
4 Podemos identificar como novelas que comparten rasgos de una estética neoindigenistas, en su voluntad de problematización, renovación y diálogo con el proyecto indigenista, los títulos de un notable corpus conformado por: Los hijos (1962), de Alfonso Cuesta y Cuesta; Entre Marx y una mujer desnuda (1976), de Jorge Enrique Adoum; Por qué se fueron las garzas (1979), de Gustavo Alfredo Jácome; Bruna, soroche y los tíos (1973), de Alicia Yánez Cossío, por señalar los momentos más representativos de una tradición.
} 
de Mama Domitila...). ${ }^{5}$ Bien podemos situar la novela de Carlos Arcos al interior de estos debates, en la invención de un texto que en el diálogo con su propia tradición la problematiza.

El encuentro de Andrés Chiliquinga con su tocayo, como lo llama, genera una serie de críticas con respecto a lo que el autor del Andrés Chiliquinga "original" ha consignado entre los guiones de su novela (muy propio del estilo icaciano): ${ }^{6}$ "Subrayar todo aquello que Icaza escribe entre guiones" es la recomendación que le hace María Clara: "Creo que Icaza, a través de esta forma de escribir, decía lo que realmente pensaba" (Arcos, p. 42). Así, la lectura y comentarios de lo que Icaza ha escrito entre guiones generan una suerte de lectura correctiva que, en la redacción de los resúmenes que Andrés prepara para su exposición en clase, se traduce en la escritura de un nuevo texto: la re-escritura de Huasipungo en clave contemporánea -qué tiene que decir un indio moderno frente a un libro que, desde una perspectiva "mishu" (mestiza),

\footnotetext{
${ }^{5}$ Mama Pacha y Mama Domitila son personajes indígenas en dos novelas de Jorge Icaza: Mama Pacha (1952) y El Chulla Romero y Flores (1952). Ambas son madres de protagonistas mestizos, en cada una de las dos novelas mencionadas. El crítico ecuatoriano Alejandro Moreano ha observado que, desde los años cincuenta, la literatura ecuatoriana vive un inacabable parricidio frente a la Generación del 30, como "una suerte de rito de pasaje que toda nueva generación debe cumplir". En clave edípica, Moreano interpreta las reiteradas condenas a la Generación del 30, así como el olvido y sepultura de Icaza.

${ }^{6}$ La crítica ha llamado la atención sobre el recurrente uso de incisos, como característica del estilo icaciano: incisos que, bajo la forma de guiones, agregan una información no directamente relacionada con el desenvolvimiento de la trama. Estos guiones precisan hasta el exceso la caracterización de un personaje, objeto o lugar, a través de la enumeración, la hipérbole, la descripción sensible de la realidad. El recurso mencionado quiebra constantemente la linealidad del relato, rompen el ritmo e interrumpen la narración a cada paso.
} 
pretende hablar acerca del mundo de sus mayores. ${ }^{7}$ Resulta significativo que el autor de las Memorias, Carlos Arcos, se inserta en la misma tradición a la que interroga y refuta, puesto que ese "lector/escritor ideal" -el Andrés Chiliquinga de hoyes una invención de su propia imaginación literaria; es decir, una construcción que responde, como en el caso de Icaza, a un conjunto de saberes y sensibilidades de matriz blanco-mestiza. Una matriz sensible y enriquecida a la luz de los debates contemporáneos -impacto del movimiento indígena, el fenómeno de la migración, los nuevos referentes en la discusión académica- que, en razón de ello, posibilita una actualización de los códigos indigenistas al interior de la economía literaria.

Esta re-escritura de Huasipungo corrige imprecisiones, completa vacíos, instala nuevas preguntas, interpela a Icaza en su imposibilidad para, en palabras del Chiliquinga contemporáneo, ver el corazón indígena: "Él no se interioriza en los sentimientos de mi tocayo" (Arcos, p. 71). El escritor Carlos Arcos, casi ochenta años después de la publicación del texto icaciano, lo reescribe en el esfuerzo por "corregir" un conjunto de afirmaciones acerca del mundo indígena en tanto

\footnotetext{
${ }^{7}$ Ya José Carlos Mariátegui zanjó la discusión, en 1928, al momento de establecer la distinción entre literatura indigenista -que "no puede darnos una versión rigurosamente verista del indio", pues se trata de una literatura de mestizos- y literatura indígena -que "vendrá a su tiempo. Cuando los propios indios estén en grado de producirla". Décadas más tarde, Antonio Cornejo Polar advierte que la literatura indigenista, en la medida en que su referente no impone su modo de expresión sino que soporta una formalización ajena, resulta tergiversadora en mayor o menor medida. Por tanto, se trata de una literatura que porta un "doble estatuto socio cultural", pues existe necesariamente un quiebre entre el universo indígena y su representación indigenista que pertenece a un universo blanco-mestizo.
} 
otredad cultural en relación con el mundo blanco-mestizo -el lugar de enunciación de ambos textos: Huasipungo (1934) y Memorias de Andrés Chiliquinga (2013)-. Se trata de una lectura exhaustiva, y afectiva, que produce un nuevo texto, uno que se instala en los intersticios, descuidos, "equivocaciones" y fracturas del original: "descubrí en mi corazón que el libro de Icaza y la historia que contaba de mi tocayo me habían agarrado. No era solo su historia, era la de los míos" (Arcos, p. 81). Justamente, a partir de una lectura que compromete las emociones, es desde donde el lector ficcionalizado por Arcos, en su nueva función de escriba, resignifica los códigos del libro leído. Una lectura que se potencia en la escritura de un nuevo texto, en diálogo con una memoria familiar mediada por la voz del Chiliquinga icaciano que visita a su lector en sueños. El fantasma de Andrés Chiliquinga provee a su tocayo contemporáneo información de carácter histórico, que permite al estudiante hacer una serie de correcciones, precisiones y descubrimientos acerca de la novela leída, en relación a su referente real que es el mundo indígena ecuatoriano -en la década de los treinta del siglo pasado, así como en el presente de su lectura.

La estrategia narrativa, que convierte al protagonista de Huasipungo en fantasma y coprotagonista de una novela contemporánea, da cuenta de una situación enunciativa que descubre al escritor no solo en calidad de lector sino como heredero de una tradición, tal como lo propone Gina Saraceni: como sujeto que se inscribe en una genealogía, al momento de contraer una deuda con respecto a su pasado. El pasado como herencia con la que es necesario confrontarse, "también como 
vOz que viene de atrás para irrumpir y desajustar el presente de los vivos" (Saraceni, 2008, p. 13). Esa herencia, en este caso el archivo de un saber literario, implica, para quien la asume, una responsabilidad que pone en movimiento un proceso de lectura e interpretación del legado, así como un trabajo de rememoración y reescritura en el presente. En este sentido, Saraceni destaca la idea derridiana del espectro como reaparición de algo que dejó de estar pero que sigue estando: "suerte de presencia anacrónica, de aparición intempestiva que desajusta y desarticula la contemporaneidad mostrando su deuda con el pasado, su actualidad inactual" (pp. 14-15). Traer de vuelta a Icaza a la escena literaria contemporánea bien puede ser leído como un tributo, como la revelación de un archivo aún disponible para nuevos proyectos de escritura y formas inéditas de trabajo con la memoria literaria: re-escritura de la herencia, fabulación del legado, creación estética que muestra el pasado como "temporalidad en proceso".

Interesante la intermitente aparición del fantasma del Andrés Chiliquinga icaciano, porque las referencias que hace de él su tocayo propicia discusiones con su interlocutora María Clara acerca del estatuto de la ficción. En tanto la novela interpela el horizonte de veracidad del proyecto icaciano, ella puede ser leída como una suerte de ajuste de cuentas con respecto a una genealogía literaria (indigenista o neoindigenista). Más aún, lo que está en discusión es la deriva fabuladora de un escritor al momento de bregar con un archivo que problematiza los códigos interpretativos de su propia tradición: allí en donde la potencia inventiva del saber literario parece desplazar la autoridad de otros discursos (el de 
la antropología, la historia, la sociología, las ciencias políticas $)^{8}$ irrumpe el fantasma de una realidad imaginada como efecto de un juego de imágenes contiguas: una imagen que interpela otra imagen en el escenario de una escritura que multiplica, y desplaza al mismo tiempo, su encuentro con lo real.

El fantasma de Andrés Chiliquinga es la figuración de una vOZ ancestral, que porta una palabra intervenida por varias generaciones de escritores: la "media verdad" de Icaza es reformulada a la luz de nuevas experiencias, tanto de vida como de escrituras: "Ya terminaste el libro del mishu Icaza, ¿ahora qué piensas? A mí me mataron, pero ya ves, igualito que el Alfonso Cánepa, el peruano [protagonista de Adiós, Ayacucho, la novela de Julio Ortega también estudiada en el curso doctoral], yo sigo andando, no porque me falten los huesos o partes de mi cuerpo, (...) también porque me pidieron los compañeros de Cuchitambo, ya te contaré" (p. 196). Al interior del pacto ficcional, el protagonista de la novela de Carlos Arcos escribe sus memorias por delegación y expreso pedido del protagonista de Huasipungo: "Hasta al mishu Icaza le va a dar gusto leerlas" (p. 211). Las Memorias adensan, actualizan e interpelan el archivo indigenista, escenifica sus protocolos de escritura y sus pactos de lectura en la coyuntura contemporánea. Sin duda, al interior de toda biblioteca se mantiene vivo el diálogo entre escritores: "Si no sabes, inventa algo que te haga dueño del pasado" (p. 199), le dice al Andrés

\footnotetext{
8 Andrés Chiliquinga observa, con respecto al saber antropológico: "Los antropólogos que pasaban por Peguche y Otavalo, le dije, iban nombrando lo que vivíamos y lo que hacíamos con otras palabras, hasta que éstas comenzaban a filtrarse en las nuestras" (p. 132).
} 
Chiliquinga de hoy la voz que viene de atrás. En el edificio de la biblioteca principal de la universidad tiene lugar una de las últimas escenas, en donde Andrés Chiliquinga advierte los miles de libros exhibidos en las estanterías, y piensa acerca de los personajes atrapados en el olvido, en el diálogo posible entre escritores y personajes. La novela recrea ese imaginario diálogo como gesto en el que se funda toda tradición. La tradición, como ya lo sabemos, es producto de un proceso creativo que se fragua entre muchas manos, en el estallido de un deseo, más que de escritura, de re-escritura: de apropiación, intervención, corrección, expansión, hurtos, montajes, de la tradición heredada.

\section{4.- En la ciudad: memoria de la tribu}

En 2008 Jorge Velasco Mackenzie publica Tatuaje de náufragos, novela que bien puede ser leída como homenaje literario a una generación -el grupo Sicoseo, en la década de los setenta y comienzo de los ochenta: escritores que consolidaron proyectos de escritura y modos de vida alrededor del mítico soda bar El Montreal, frente al parque Centenario en Guayaquil. Se trata, simultáneamente, de un homenaje a la ciudad, en el entramado de una escritura que aúna poemas y cuadros de artistas guayaquileños con fragmentos del espacio urbano que sobresalen como soporte de una memoria generacional. En el presente narrativo, 2005, Zacarías Lima, médico forense, se ve acosado por un sin número de extravagantes muertes que van minando una ya frágil salud 
emocional. En el marco de estas incomprensibles muertes, cuerpos tatuados y mensajes en clave, la novela se acerca al relato policial: siguiendo los códigos del género, el poeta y cronista Jorge Martillo, amigo del doctor Lima Paladines e integrante de la banda del Montreal, interviene en calidad de agente secreto junto a su ayudante el pintor Lizandro Mendoza y la episódica asistencia del escritor Javier Vásconez. Paralelamente, la novela relata algunos hechos que marcaron la escena política del país, en el curso de los primeros años del nuevo siglo: el movimiento civil de los Forajidos y la caída del ex presidente Lucio Gutiérrez, marchas y contramarchas ciudadanas, en medio de una situación de crisis y malestar social que, desde la perspectiva enunciativa, se agrava con la clausura de El Montreal. En muchos sentidos, la novela es el relato de los años de esplendor del bar, frecuentado por poetas y pintores, así como de su naufragio y hundimiento. Es justamente este hecho el detonante de un ejercicio de infatigable rememoración alrededor de un lugar y una época, cuyo eje vertebrador es la figura y los poemas de Fernando Nieto Cadena, exiliado en México en el presente de la narración. Importa resaltar que los escritores, cronistas y pintores mencionados portan el nombre propio de su referente real: artistas representativos de la escena ecuatoriana contemporánea.

Observa la crítica argentina Leonor Arfuch que memoria y archivo son dos significantes emblemáticos del corte temporal que inaugura el nuevo milenio:

Quizá por la carga mítica del calendario, que gusta enfatizar en fines y principios, quizás por la densidad abrumadora 
del siglo que pasó y el vacío prospectivo del que viene (...), los ritos del no-olvido, la rememoración, la recuperación, el inventario, se multiplican en las últimas dos décadas, involucrando diversamente a las sociedades, tanto en lo que hace a las instancias de decisión política, mediática y cultural, como a las práctica comunitarias, la producción académica y la experimentación artística (2007, p. 77).

Sin duda, Tatuaje de náufragos participa de esta voluntad de rememoración de la que habla Arfuch, en el logro de una escritura que conjuga una variada tipología de memorias: urbana, generacional, estética. Como todo trabajo con la memoria, el horizonte de reflexión es el tiempo presente que destaca algunos sucesos del pasado en el esfuerzo por dotar de sentido, en este caso, a un conjunto de prácticas percibidas como argamasa afectiva de una cofradía de amigos: lecturas compartidas, vida bohemia, publicaciones en sincronía generacional, recorridos urbanos. Hacer pervivir en la memoria colectiva un particular rostro de la "ciudad de los manglares" y un modo de vivirla deviene detonante de ficcionalización y escritura: el paisaje urbano se transforma, y quienes lo dinamizaron en décadas precedentes van muriendo. Frente a dinámicas de pérdidas y olvido se impone la fábula, la narrativización de ese pasado que amenaza con perderse entre viejas fotos $y$ experiencias dispersas - de una comunidad generacional que va desapareciendo entre el exilio y la muerte.

La fuerza performativa de la memoria deviene así novela en clave de homenaje, a una ciudad y a una generación. Es en este sentido que Tatuaje de náufragos participa del relato histórico, la crónica, la biografía, el testimonio, la novela de artista. En esta perspectiva, el logro más llamativo de la novela de Velasco 
Mackenzie es su riqueza intertextual: el archivo que la sostiene es uno de carácter estético. Óleos y poemas de artistas guayaquileños constituyen el archivo que incesantemente hurga el novelista, en su esfuerzo por legitimar y dotar de veracidad a su escritura. Por mediación de la memoria, el arte deviene documento de credibilidad, archivo que sustenta la proliferación incesante de una escritura al interior de un movimiento de autofagia creativa: homenaje y re-escritura como andamiaje de una tradición literaria en constante renovación. El doctor Zacarías Lima es un lector voraz, escritor en ciernes, alter ego de Velasco Mackenzie, uno más de los asiduos visitantes del Montreal. En su consultorio médico cuelga sobre una pared la galería de escritores preferidos, en donde lucen los retratos de Pablo Palacio, Juan Carlos Onetti, Franz Kafka, Fernando Nieto. Dispersos a lo largo de la novela hay un sinnúmero de guiños literarios que entretejen una suerte de código secreto. Uno que garantiza cierta complicidad con el lector, a la vez que estructura la trama anecdótica y define a los personajes en varios sentidos. Una de las riquezas de la novela es el sensible y logrado diálogo con versos y fragmentos de los libros que hacen parte de la biblioteca personal del médico forense. Los textos leídos se insertan en la trama novelística a modo de cita, detonante de memoria y reconocimiento. Destaca en este sentido el diálogo con De última hora, tarjeta curricular extraviada, de Nieto Cadena: los versos originales, citados en la novela, dicen así: "Hubo una vez:/ Una isla un muelle un parque una iglesia una casa una cantina un restorán/ un hotel un prostíbulo un estadio una escuela una farmacia una biblioteca (...)" (Velasco Mackenzie, 
p. 106). Zacarías Lima/Velasco Mackenzie reescribe los versos, inserta otros, agrega incisos entre signos de puntuación ausentes en el texto original. Desde la apropiación afectiva que hace del poema Zacarías Lima, los versos son re-escritos en diálogo con la ciudad que es lugar y horizonte de escritura:

Hubo una vez:

Una isla, la del Carmen en el Golfo de México donde el poeta vivía, atacado por una diabetes que lo estaba matando. Un muelle, en el malecón del río dela ciudad de los manglares. Un parque, Centenario de años frente al bar Montreal. Una iglesia, de la Victoria, en cuyos alrededores creció huérfano de padre. Una casa delos abuelos atestada de libros. Una cantina, el salsa na má, donde solía ir a escuchar música tropical. Un restorán: El Piave, antiguo y desaseado pero con mesitas de mármol. Un hotel de paso llamado Cotopaxi, como el volcán cerca de Latacunga. Un prostíbulo que no era otro sino La puerta de fierro, en la Octava y Portete. Un estadio, el viejo Modelo donde se jugaron los mejores clásicos del astillero entre Barcelona y Emelec (...). (Velasco Mackenzie, p. 108)

La novela de Velasco entra en diálogo con un archivo literario que se actualiza en la perspectiva del presente narrativo: la operación intertextual provoca una lectura que propone nuevas condiciones de inteligibilidad con respecto al texto original, modela una nueva escritura a la luz de otra que la antecede. Escritores y pintores aparecen con sus nombres reales, insertados en la trama novelística, junto a la obra que los ha convertido en paradigma de una memoria colectiva; referentes de una generación, una época, una tradición artística: Nieto Cadena, Jorge Martillo, Dalton Osorno, Agustín Vulgarín, Fernando Artieda, el grabadista Walterio Páez, los 
pintores León Ricaurte, Juan Villlafuerte, César Andrade Faini, Enrique Tábara, entre otros. Son nombres que perduran entre los intersticios de una memoria que monumentaliza y otra referida al orden de los afectos, el sentido de filiación y pertenencia. Señala Pierre Bourdieu que el nombre propio "instituye una identidad social constante y durable que garantiza la identidad del individuo biológico en todos los campos posibles donde interviene en calidad de agente, es decir en todas sus historias de vida posibles" (p. 10). Así, todavía en diálogo con Bourdieu, es el nombre propio lo que garantiza la pervivencia de los diferentes agentes sociales, a través del tiempo y la unidad a través de los espacios. De allí que la sola enunciación del nombre propio real de escritores y pintores, libros, cuadros, lugares emblemáticos, produce en la novela un efecto de perdurabilidad. El nombre propio conecta épocas diferentes, anuda las rupturas y discontinuidades propias del tiempo histórico, provoca en el lector un sentido de familiaridad que actualiza el archivo de su propia formación lectora. En razón de ello, reconocer el nombre propio de sujetos históricos reales provee de fuerza ilocutoria a la narración. Los rostros del pasado adensan el tiempo presente borrando las fracturas que la muerte instala; iluminan, en la evocación, los lugares que albergaron a sus cuerpos. Esos lugares devienen así referentes y puntos de apoyo de una memoria compartida, que porta las huellas de los afectos y de la intimidad en el entretejido de lo público y lo privado. Leamos a Velasco:

Comprobó esa noche final, que era verdad lo que el viejo Hugo Mayo había dicho cuando le preguntaron por qué 
salió del país. "Los mejores viajes son esos que se hacen en la memoria, caminando desde la sala al cuarto de baño". Ahora su memoria viajaba. El mejor recuerdo que Zacarías Lima poseía del poeta era su cabeza de lechuza asomándose por una ventanilla del Palacio Municipal, parecía un reo oteando por la rejilla de una mazmorra. "Espectáculos", se leía en un cartel sobre aquel ventanuco donde él oficiaba de inquisidor de circos, bailes públicos, ferias y operetas, duelos falsos [...]. Los gruesos lentes de don Hugo, como lo llamaba, su cuello de pavo y su voz ronca, aún se hallaban frente a él (p. 157).

Especial lugar ocupa el maestro pintor César Andrade Faini, cuyo óleo titulado Carnaval parece cifrar las claves necesarias para resolver las muertes, extraños mensajes e informes que acosan al doctor Zacarías. En verdad, si invertimos este juego de espejos es posible pensar que la novela de Velasco Mackenzie no es sino la reescritura de un cuadro, un ejercicio de traducción en el que las palabras fabulan la historia que formas y colores narran de otra manera: escritura celebratoria y admirativa, a la vez. Se produce así sugerentes vasos comunicantes que explicitan una hiperconciencia narrativa acerca de los caminos que entrelazan la realidad y la ficción: "En verdad, nunca posaste para el cuadro de don César, él solo imaginó la escena y la plasmó, apareciste tú, 'Trista' huyendo de ti y el brujo, todo en un patio interior, un día de carnaval. No olvides, a veces el arte también inventa la realidad" (Velasco Mackenzie, p. 233). Son palabras que Velasco coloca en boca de Jorge Martillo en su rol de poeta detective. Finalmente, el caso que, flexibilizando las características del género, podría definirse como policial, no llega a resolverse. Los informes que entrega Martillo se insertan como capítulos 
de la novela, así como los poemas, óleos, algunas esculturas y lugares de la ciudad en la consecución de una escritura que, sin dejar de reflexionar sobre ella misma, cautiva la atención del lector. Contagia el placer de su propio autor a quien no resulta difícil imaginar divertido en la lúcida manipulación de un archivo estético, a la vez que brega con la inevitable nostalgia que supone trasegar tiempos y afectos desaparecidos. "Yo no confío mucho en las palabras escritas en los diarios. El universo poético es el único en que confío” (p. 139), solía repetir Zacarías Lima. Es ese universo el que alienta Tatuaje de náufragos en el esfuerzo por rememorar una tripulación ausente, aquélla que pobló los días y las noches de complicidades y lecturas en el Montreal.

\section{5.- Todas las escrituras la escritura}

La desfiguración Silva, de Mónica Ojeda (2014), obtuvo el Premio Alba Narrativa que convoca el Fondo Cultural Alba y el Centro Cultural Dulce María Loynaz. La acción principal, podría decirse, es la narración del rodaje de un cortometraje por parte de un grupo de jóvenes universitarios en Guayaquil. La escritura procura, desde diferentes ángulos narrativos $y$ formatos discursivos, juntar los fragmentos de una historia, exponer los sucesos tal como son recordados por quienes los protagonizaron. Las diferentes intervenciones narrativas desde la mirada en retrospectiva de cada uno de los

personajes- fracturan la linealidad del relato, producen un efecto de oralidad testimonial, perforan la escritura a partir de 
constantes digresiones en torno al cine, la literatura, el arte conceptual. Esas digresiones saturan al texto a modo de un acumulado de conversaciones sumergidas: la novela contiene capítulos que son parte de entrevistas, un cuaderno de rodaje, un guión de cortometraje, poemas, un ensayo literario, una biografía. Los personajes discuten y reflexionan sobre pintura, arte conceptual, cine, literatura, y lo hacen porque es el mundo en el que se mueven: son estudiantes de literatura, de teatro, profesores de cine, periodistas. Los múltiples diálogos y reflexiones que hacen referencia a textos literarios y cinematográficos desbordan el texto como estrategia en la definición de los personajes. La novela apuesta por una escritura que interroga los alcances de su propia deriva discursiva, en tanto la narración va tejiendo nexos entre películas y recuerdos. Como si la novela misma se construyera al interior de un entramado intertextual, en donde el saber desplegado en torno al arte no es mero referente sino clave de lectura a modo de señaléticas que ordenan un mapa conceptual, una bitácora de exploración creativa.

Tres hermanos, cinéfilos y lectores empedernidos, roban un misterioso guión cinematográfico, inventan un personaje histórico que nunca existió (Gianella Silva), fabulan su biografía como la única mujer del grupo tzántzico, ${ }^{9}$ directora y

\footnotetext{
${ }^{9}$ El grupo tzántzico encabezó, entre 1962 y 1969 -en el marco de la Junta Militar del 63 al 66- el movimiento de "parricidio intelectual" y de ruptura que protagonizó la escena cultural en Quito, en el esfuerzo por negar y desacreditar la herencia cultural occidental y cristiana, impuesta por la colonización. El tzantzismo fue un movimiento iconoclasta y de negación total, marcado por la acción, la demanda de presente y el sentido de la urgencia, que propuso nuevos modos de asumir la literatura, las tareas del intelectual y el ejercicio de la militancia política, en el marco de una búsqueda que devino primordial: la construcción de una "auténtica cultura nacional y popular". El nombre del grupo remite
} 
guionista, cuyos cortometrajes habrían sido reseñados en la histórica revista Pucuna. ${ }^{10}$ El fantasma de Silva complejiza la escritura, a la vez que la interroga en sentido lúdico: reseñas, episodios biográficos, un guión de su autoría, arman un archivo apócrifo alrededor del cual se construye la novela: el entramado intertextual (cabe decir también intervisual) deviene escenario de un enigma que actualiza la pregunta por el autor y el sentido de originalidad en todo acto de creación: "El arte es un constante rehacer lo que ya se ha hecho, un auténtico proceso de falsificación" (p. 108), sugiere Irene, parte del clan conspirador de los hermanos Terán. Los personajes son fundamentalmente lectores y espectadores de cine, y es esa práctica la que agencia un proyecto que sitúa la lectura como acto creativo, desde donde es posible reinventar la historia. Ese proceso, que deviene hilo invisible de la novela, sostiene la estrategia autoral: la escritura evidencia el diálogo constante con otros textos, el escritor en su rol de lector/detective/fabulador/plagiador. Referentes de una biblioteca/videoteca compartida se cuelan en la narración, la invaden, trasiegan la anécdota, exhiben las múltiples complicidades de la escritura cinematográfica con la literatura contemporánea, trazan el espacio de un diálogo que hace posible la invención de nuevas ficciones. Detrás de la figura ficcional de Gianella Silva, la autora escenifica el proceso

a "tzantza": cabeza reducida, como resultado de la práctica del pueblo indígena Shuar de reducir, y conservar, las cabezas de sus enemigos.

${ }^{10}$ Pucuna fue la revista emblemática del grupo tzántzico. Su director fue el poeta Ulises Estrella. Se publicaron un total de 9 números, entre 1962 y 1968. Pucuna es el nombre de la cerbatana con la cual los Shuar, en la Amazonía ecuatoriana, lanzaban sus dardos envenenados para reducir cabezas. 
creativo: como si la ficcionalización no fuera sino siempre la re-escritura de otro texto, la deformación de una historia, la desfiguración de un referente (real o ficticio).

La historia empieza con la escritura -me dijo Duboc por teléfono-. Tienes que entenderlo o estás jodido: lo que ellos querían era cambiar una parte de la historia, agregar una mujer a los tzántzicos, una cineasta brillante en donde no hubo cineastas brillantes; una mujer en donde solo hubo hombres y también inventar a la mejor creadora que haya existido jamás en este país de mierda (p. 64).

La historia comienza con la escritura ciertamente, o, cabría precisar, con la reescritura, como parece sugerir el título del cortometraje, Amarona jadeando en la gran garganta oscura, pues se trata de un verso de Alejandra Pizarnik, del poema "Formas". El cortometraje es autoría de los hermanos Terán, alrededor de cuyo proceso creativo transcurre parte de la novela. Una constante reflexión acerca del acto creativo como resultado de un engranaje metonímico atraviesa la novela, en tanto cada referente abre la escritura hacia nuevos mundos, articula inesperados matices en la comprensión del entramado anecdótico, en el marco de un escenario que dinamiza prácticas de influencia, parodia, cita, como mecanismo de aprendizaje, estrategia lúdica que funda y a la vez quiebra toda tradición. El personaje central, el fantasma de Gianella Silva, es inventado como miembro olvidado del movimiento tzántzico. El poeta Ulises Estrella aparece como personaje tangencial de la novela, y los demás miembros del movimiento vanguardista de los años sesenta son aludidos con nombre propio. Esos nombres sitúan la novela en la historia, movilizan referentes del entramado cultural ecuatoriano del siglo XX. El nombre 
propio hace posible el encuentro del lector con fragmentos de la historia real, puesto que opera como huella/testimonio de un acontecer. Si por un lado, el nombre propio de cineastas y guionistas detona el fluir de un pensamiento metacrítico, por otro, y de manera simultánea, el nombre del movimiento tzántzico, el de Ulises Estrella y de otros, articulado al motivo que empuja la trama anecdótica, se relaciona con una idea central que impulsa la novela desde la enunciación de su título: la desfiguración de la historia, del nombre propio, del referente real, desde la escritura.

Dos personajes portan el mismo nombre: Gianella Silva, escritora y encargada de la dirección fotográfica del cortometraje, y la Gianella Silva tzántzica, personaje apócrifo del movimiento, conjugan algo parecido a un juego de espejos, al interior de un divertido entramado intertextual que indaga en la problemática del simulacro y las repeticiones, al tiempo que desestabiliza toda certeza de representación y semejanza: "La verdad, la única en este desierto de repeticiones, es que mi nombre no es Gianella Silva: es Gianella Silva", frase que deshace la vieja equivalencia entre semejanza y afirmación, tal como lo planteó Foucault en la lectura que hizo de Magritte. Este juego que inventa una mujer allí en donde nunca existió, en la pretensión de reivindicar la única mujer tzántzica, es un poco reírse de la historia, desestabilizarla desde una interrogante con marca de género. Esa interrogante parece situarse al inicio de la escritura, casi como detonante en el señalamiento de un hueco, de un contenido vacío frente al cual la escritora apela no a la historia "real", sino a la desfiguración de ella desde el deseo y la experiencia lúdica. 
Los autores de las novelas aquí discutidas son, ante todo, lectores de una tradición narrativa: escriben desde una biblioteca compartida, cuyos catálogos parecen desordenarse y cobrar una nueva fisonomía en virtud de una particular relación afectiva con personajes, libros y escritores que pueblan nuestra memoria literaria. Como situados al interior de un "círculo mágico", estos escritores modifican y reinventan el archivo que la institución literaria celebra y también olvida. Reconocer en la lectura a escritores en calidad de personajes despierta en nosotros eso que Halbwachs denomina "el sentimiento de lo ya conocido". Este juego de apropiaciones y reminiscencias devuelve a la escritura sus funciones propiamente mágicas: "el encanto a distancia y la comunicación con los muertos", en palabras del filósofo alemán Peter Sloterdijk, a propósito de una reflexión acerca de la producción de conocimiento y los "círculos de resonancia" (p. 248). Una comunicación que hace posible habitar la tradición para reinventarla. Las novelas leídas rozan la estrategia de re-escritura en el diálogo que ensayan con la tradición narrativa ecuatoriana. La mexicana Cristina Rivera Garza invita a pensar la re-escritura como una práctica productiva que deja al descubierto la escritura como trabajo en comunidad y estrategia de apropiaciones:

Se trata, así entonces, de entender el trabajo de la escritura como una práctica del estar-en-común (...). Se trata, 
finalmente, de entender a la escritura siempre en tanto reescritura, ejercicio inacabado, ejercicio de la inacabación, que, produciendo el estar-en-común de la comunalidad, produce también y luego entonces el sentido crítico -al que a veces llamamos imaginación- para recrearla de maneras inéditas (p. 36).

Las novelas del corpus aquí seleccionado trabajan la escritura como proceso creativo que re-inventa/re-escribe/actualiza un texto anterior, uno que deviene paradigma y clave de lectura: "Porque los autores son muchos, pero la literatura es un mismo organismo" (Ojeda, p. 100).

\section{Referencias Bibliográficas}

Arcos, C. (2014). Memorias de Andrés Chiliquinga. Quito: Alfaguara.

Arfuch, L. (2007). "Arte, memoria y archivo”. Crítica cultural entre política y poética. México: FCE.

Barthes, R. (1994). El susurro del lenguaje: más allá de la palabra y la escritura. Barcelona: Paidós.

Bourdieu, P. (s/f). La ilusión biográfica. La Paz: Universidad Mayor de San Andrés.

Cárdenas, E. (2008). El pinar de Segismundo. Quito: Ministerio de Cultura.

Cueva, A. (1981). Entre la ira y la esperanza: Ensayos sobre la cultura nacional. Cuenca: Casa de la Cultura Ecuatoriana, Núcleo del Azuay.

Derrida, J. (1989). Memorias para Paul de Man. Barcelona: Gedisa. 
Derrida, J. (1997). Mal de archivo. Madrid: Trotta.

Derrida, J. (2003). Espectros de Marx. El estado de la deuda. El trabajo del duelo y la nueva Internacional. Madrid: Trotta.

Halbwachs, M. (2004). Los marcos sociales de la memoria. Barcelona: Anthropos.

Moreano, A. (2008). "Entre la permanencia y el éxodo". AAVV. La palabra vecina: encuentro de escritores Perú-Ecuador. Lima: UNMSM/Centro Cultural Inca Garcilaso, pp. 85-110.

Mussó, L. C. (2011). Oscurana. Quito: Antropófago.

Ojeda, M. (2014). La desfiguración Silva. La Habana: Editorial Arte y Literatura.

Ricoeur, P. (2004). La memoria, la historia, el olvido. Buenos Aires: Fondo de Cultura Económica.

Rivera Garza, C. (2014). "Desapropiadamente: escribir con otros hoy". Escribir no es soledad. México: Universidad Nacional Autónoma de México / Coordinación de Difusión Cultural Dirección de Literatura, pp. 30-46.

Saraceni, G. (2008). Escribir hacia atrás. Herencia, lengua, memoria. Rosario: Beatriz Viterbo.

Sloterdijk, P. (2009). "Transmisión de pensamiento". Esferas I. Madrid: Siruela.

Velasco Mackenzie, J. (2008). Tatuaje de náufragos. Quito: Ministerio de Cultura, 2008. 